\title{
山东莱阳中生代晚期昆虫群及其 古生态特 征 ${ }^{*}$
}

\author{
张俊峰
}

(山东省博物馆, 济南 250012 2

\section{关鹳诃山东莱阳、中生代晚期、昆、虫群、古生态}

我国山东莱阳发育有一套非海相沉积地层. 其中, 在莱阳组的薄层页岩和纸片状页岩中 富含昆虫化石. 莱阳组的沉积时代目前尚有争议,有人把其归入晚侏罗世,亦有人认为是早白 普世. 有关的交通位置和地质资料已经发表 ${ }^{[1,2]}$, 这里不再鳌述. 这个地区是我国昆虫化石研 究的发源地, 早在本世纪 20 年代, 就有中外学者报道过产于莱阳组中的昆虫化石 ${ }^{[3,4)}$. 然而, 大量的研究成果是在最近几年内完成的 ${ }^{[5-13)}$, 目前, 已有 9 个目 60 种昆虫化石已经发表. 从 1984 年至 1990 年, 本文作者通过在这个地区多次反复的野外工作, 所采集到的昆虫化石标 本已达数干块, 计有 300 余种, 分别隶属于蜻蜓目 (Odonata)、蚌蠊目 (Blattaria)、直翅目 (Orthoptera)、革翅目 (Dermaptera)、同翅目 (Homoptera)、异翅目 (Heteroptera)、缕翅目 (Thysanoptera)、鞘翅目 (Coleoptera)、脉翅目 (Neuroptera)、蛇蛉目 (Raphidioptera)、长翅 目 (Mecoptera)、毛翅目 (Tricoptera)、膜翅目 (Hymenoptera) 和双翅目 (Diptera) 等 14 个目. 这批材料无论是在种类丰富程度上, 还是在标本保存的完美程度上, 都是世界范围内中 生代昆虫化石产地所罕见的, 为我们深人研究东亚中生代晚期昆虫群的总体面貌特征和恢复 当时的古地理、古气候、古生态特征提供了可靠的依据.

在这个昆虫群中, 鞘翅目的种类最丰富, 远超过 100 个种; 其次, 膜翅目和双翅目的种类也 较多, 各自分别具有数十种; 异翅目和同翅目的种类也很丰富. 绝大多数昆虫属于陆生种类, 水生昆虫有十余种. 其中, 植食性种类最多, 伴有相当数量的捕食性和寄生性昆虫. 而水生 种类以肉食性为主. 根据现代昆虫生态学的知识, 这个化石昆虫群中的绝大多数种类应是森 林沼泽区的类型, 在莱阳组中所发现的标本属异地埋葬; 少数神类系淡水湖泊中的分子, 属原 地埋葬. 由于在这个昆虫群中存在着许多中生代特有的高级分类群(科级或科级以上分类阶 元), 因此, 它明显不同于晚白王世及其第三纪的昆虫群, 后者基本上呈现了现代昆虫区系的面 貌, 几乎所有的化石种类都可归人现生科之中. 另一方面, 中生代晚期的这个昆虫群又明显有 别于中生代早期和古生代的昆虫群, 前者存在着若干在昆虫演化上属于较为先进的分子, 如双 翅目的扁足蝇类 (Platypezidae), 膜翅目的泥蜂类 (Sphecidae) 和姬蜂类 (Ichneumonidae), 脉翅目的草蛉类 (Chrysopidae) 等. 而后者仅有少量的类型能够归人现生科, 且通常是较原 始的类群, 大量的种类都是属于十分原始的在中生代晚期以前就绝灭了的分类群. 我们可以

本文 1991 年 4 月 15 日收到. 1991年7月20日收到倠改稆.

* 国家自然科学基金资助项目. 


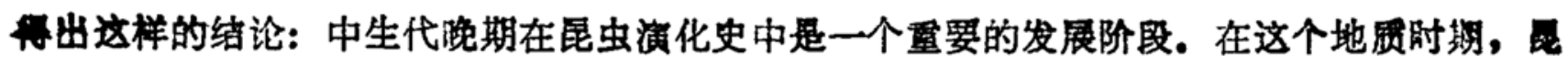
虫群的总体面貌既保留了中生代早期昆虫群的某些原始类群, 又具有现代昆虫区系中的某紧 较进化的类型, 大量的则是属于中生代晚期特有的分子. 这个时期的昆虫群属于中生代早期 和现代昆虫群之间的一个过渡类型.

根据生物地层学和沉积岩石学的特征, 可以做出以下推断: 在中生代晚期, 山东莱阳盆地 一度是一片水面十分开阔的宁静的浅底淡水湖泊. 周围地势较为平坦. 气候温暖潮湿, 届于 亚热带. 湖中水生植物军见. 水生动物主要是水生昆虫和鱼类, 还有少量的腹足类和叶肢介. 它们通常不在湖的中心, 而是在近岸水域繁行生息. 岸边通常是沼泽地带, 以草木植物木悈类 (Equisetaceae) 和水龙骨类 (Polypodiaceae) 为主. 远处坡地是林区, 主要以高大的木本植 物松柏类 (Coniferales) 为主, 还有少量的银杏类 (Ginkgoales) 存在 ${ }^{2}$.

陆生昆虫遍及森林和沼泽区. 其中, 群集隐翅幽蚊 (Chtronomaptera gregaria) 和纤细 隐翅幽蚊 (Ch. vesca) 是优势种, 个体数目巨大. 水生昆虫除了上述两种幽蚊的幼虫和蛹之 外, 尚包括大型捕食性甲虫长足刺甲 (Coptoclava longipoda), 肉食性各种蝽类: 莱阳中蝽 (Mesolygaeus laiyangensis), 锹形华唇仰泳蝽 (Clypostemma xyphiale), 山东卡拉达划蝽 (Karataviella shandongensis), 山东开翅蝽 (Schizopteryx shandongensis) 和湖泊开翅蝽 (S. lacustris $)^{[14]}$. 其中, 群集隐翅幽蚊、纤细隐翅幽蚊的㛚和莱阳中蝽的幼虫和成虫数基甚 丰, 是无矤予问的优势种. 同时, 长足刺甲的数量仅略低于上述各种, 而山东开翅蝽和湖泊开翅 蝽的标本数量也很多, 容易采获. 根据生物地层学上的特征, 可以作如下推断: 在莱阳湖形成 的初期, 水生昆虫由群集隐翅幽妏的幼虫和㛚、长足刺甲、莱阳中蝽、锹形华展仰泳蝽、瘦华唇 仰泳蛘 (Clypostemma petila) 和山东卡拉达划蝽组成. 其中, 仰泳蛈类和划蝽类的个体数 量甚少. 在这个湖泊发展的中期, 山东开翅蝽出现, 此时, 除了数疃明显锐减的群集隐翅幽蚊 的幼虫和蛹以及莱阳中蝽外, 其余的水生昆虫几乎绝迹. 其后, 当湖泊开翅蝽出现时, 山东开 翅蝽灭绝, 而莱阳中蛈、长足刺甲、群集隐翅幽蚊和纤细急翅幽纹的幼虫和蛆达到最繁盛时期, 其余水生昆虫消失. 京时, 陆生昆虫, 无论是种类和个体数量, 呈鼎盛状态。在莱阳湖的末期, 仅有少量的莱阳中蝽和群集隐翅幽姣的幼虫和蛹在水中生存. 通过以上分析和推断, 那末, 莱 阳湖的古生态系 (Palaeoecosystem) 可以恢复: 群集隐翅幽蚊和纤细隐翅幽蚊的幼虫和蛹主 要以水中微生物为食, 同时, 可能尚具有食腐性. 它们是这个水体中动物蛋白质的提供者, 可 以被其他肉食性水生动物所吞食. 那些水生蝽类主要以这些幼虫和蛹为食. 由于长足刺甲具 有明显庞大的虫体 (体长通常在 $30 \mathrm{~mm}$ 以上), 强壮的捕捉式前足和能够快速泳动的浆状中、 后足, 它们很可能更喜欢捕捉泳动中的各种蝽类, 主要以莱阳中蝽作为食物来源。在现代的湖 泊或池塘中, 大型游泳型的捕食性甲虫, 如龙虫 (Dytiscidae) 和水龟虫 (Hydrophilidae), 通 常是羊鱼业的害虫. 因此, 我们完全有理由推测, 长足刺甲更喜欢捕捉狼䲕鱼（Lycoprera sp.) 和中华弓鯺鱼 (Sinamia sp.) 的幼鱼. 而这些种类不多的鱼类 ${ }^{2)}$, 可能主要以群集隐翅幽 蚊和纤细隐翅幽蚊的幼虫和蛹作为进食对象, 但也不能排除有捕食水生蝽类、腹足类和叶肢介 的可能性.

1) 槒物化石标本承蒙中国科学完南京地质古生物研究所孙草同志监定.

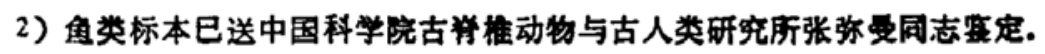


对于陆生昆虫的生态学特征的恢复, 由于其制约因素颇为复杂, 目前难以全面讨论. 但 是, 但据这个昆虫群种类颇为丰富的标本,我们至少可以作出以下推断：天敌昆虫以蜻娫目、 蛇蛉目、脉翅目和异翅目中的某些捕食性的蝽类为主,它们直接捕捉某些植食性的昆虫, 例如 同翅目中的蚜类, 双翅目中的蚊类等. 寄生性昆虫以膜翅目中的姬蜂类和泥蜂类等为主, 它们 既可以以其他昆虫作为寄主, 把卵产于其他昆虫的体内, 也可以直接刺杀某些种类的昆虫,以 其体内营养物为食. 由于我们已经采集到一块与昆虫化石伴生的蜘蛛标本和一块鸟类羽毛标 本, 因此, 也有充分的理由相信, 当时在莱阳湖岸旁和坡地的林间存在着㚳姝和鸟类, 它们都 是昆虫的重要天敌, 对昆虫(包括那些天敌昆虫)的种类和个体数量的多家起着直接控制的作 用.

根据现代昆虫学的知识, 绝大多数种类的昆虫具有较短轻的生命周期, 迅速的演化和以各 种形式,其中包括以飞翔的方式,进行快速的迁移. 因此,有不少种类是面积广阔的动物区, 勘 至是全球性的广布种. 而它们迁移扩散的时间较其他无脊椎动物明显短暂, 在地质历史上可 以忽略不计. 东亚中生代晚期“热河生物群”中的昆虫群通常称之为类虸游群 (Ephemeropsis fauna), 其中有不少种类属于当时的广布种, 对陆相地层的划分和对比提供了重要的生物学方 面的依涺. 根据目前的资料, 这个昆虫群可以划分为三个组合, 分别代表早、中、晚三个阶段》, 即: 曼来摇蚊组合 (Manlyamia Assembladge), 古箭蜓组合 (Palaeogomphus Assembladge) 和中蝽组合 (Mesolygaeus Assembladge)，第一个组合主要包括大北沟曼来摇蚊 (Manlyamia

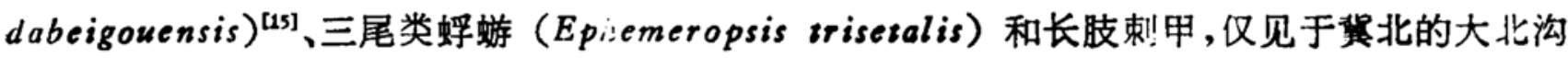
组. 第二个组合主要包括下唇古箭蜒 (Palaeogomphus labius) ${ }^{2}$ 和三尾类蜉竹, 产于辽西的 义县组和河南的南召组. 第三个组合包括种类十分丰富的昆虫, 以莱阳中蝽、群集隐翅幽蚊; 纤细隐翅幽蚊、长足刺甲为主, 尚包括下列的广布种: 锹形华唇仰泳蝽、前缘伪螑 (Pseudo acrida costata) 和全近䖮 (Panaphis circa) 等,在我国华东、东北、西北以及蒙古人民共和国 和苏联西伯利亚外加尔等地的相关地层中同时存在. 例如, 浙江的寿昌组、安徽的岩塘组、 江西的石溪组、北京西山的卢尚书坟 (一卢尚坟)组、辽宁的九佛堂组、内蒙古的固阳组、陕甘宁 地区的六盘山群和甘肃的新民堡群等. 这些盆地在中生代晚期都具有大型的湖泊, 它们与莱 阳湖应大体等时, 本文倾向于归入晚侏罗世晚期. 不同盆地的昆虫化石种类虽然不尽相同, 都 有不少地方性类型, 但就其总体面貌特征来分析, 与莱阳化石昆虫群的面貌一致, 应属于同一 个昆虫生物区,都是“热河生物群”的重要组成部分. 需要指出的是, 广为人知的三尾类娐游和 长足刺甲两个种虽然是这个生物群的重要分子, 但它们生存的时代相对于其他昆虫种类来说 较长, 前者发现于类虸蝣群的早、中阶段, 后者在早中晚三个阶段都能生存, 甚至可以上延到早 白垔世的吉林大拉子组中.

在晚侏罗世晚期,我国北方湖相沉积中纸片状页岩颇为发育,其昆虫化石保存精美, 但同 时期江南湖相沉积物以泥㟧为主, 即使有页岩, 其层理发育程度也不如江北地区, 昆虫化石保 存通常为碎片. 究其原因, 主要还是因为江北的湖水多为宁静状态, 水动力条件很弱, 而江南 的湖水由于各种因素的影响, 处于动荡之中.

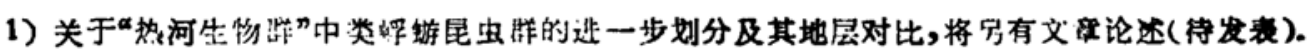

2)原属名为 Archueogomphus Lin, 已为现生屈占用,本文以 Palaeogomphus 代简. 


\section{来文 文}

[1]张俊转, 古生物学报,26(1987),595-603.

[2] Zhang, J., Mesozoic Research, 2(1990), 237-247.

[3] Grabau, A. W., Bull. Geol. Surv. of Chima., 5(1923), 164-181.

[4] Ping, C., Pelacontologia, 13(1928), 1-50.

[5]洪友炎,地层古生物论文虫:(11 辑),1984,31-41.

[6]洪友綘、王文利, 现代地质,2(1488),386-392.

[7]杨策比、洪友崇, 现代地质, $4(1990), 15-26$.

[8] 张俊㐘,山东地质,1(1985),23-39.

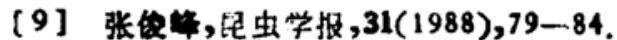

[10] 张俊辏, $r$ 生物学报, 28(1989),344-358.

[11] 张俊逢, 中牙枓学, B 转, 1990,11: 1306-1310.

[12] 张俊终、张生、刘德正、上官义宁,山东地质,《(1986),14-39.

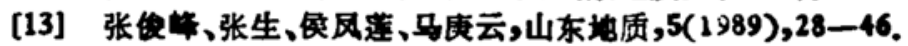

[14] 张统苦, 古生物学报, 3^(1991),6:679-694.

[15] 张俊者,古生物学报,30( 1991),5:556-564. 